\title{
HEMOGLOBIN-ALBUMIN CO-POLYMERS FOR BLOOD SUBSTITUTES: INCREASING THE REPRODUCIBILITY OF THE POLYMERIZATION REACTION
}

\author{
FLORINA SCURTU ${ }^{a}$, BOGDAN TEBREAN ${ }^{\mathrm{b}}$, MARIANN KINGA \\ ÁRKOSI ${ }^{a}$, ADRIAN IONELE ${ }^{a}$, RADU SILAGHI-DUMITRESCU ${ }^{a^{*}}$
}

\begin{abstract}
Reticulation/polymerization of proteins using bifunctional reagents, with glutaraldehyde as a typical example, has a wide range of applications - of which HBOC (hemoglobin/hemerythrin based oxygen carriers) are illustrative. Here, the kinetics of the derivatization reaction of hemoglobin and albumin with glutaraldehyde are revisited, in order to establish the optimal conditions such as concentration of protein and derivatization agent for which the final product can be a reasonable candidate for blood substitutes. A purpose-built mixing device is described, which allows automated mixing of up to four reagents in less than 100 milliseconds, allowing for polymers with a more reproducible molecular weight.
\end{abstract}

Keywords: hemoglobin, glutaraldehyde, bovine serum albumin, blood substitutes, mixer, polymerization

\section{INTRODUCTION}

Able to transport oxygen outside of the red blood cell, native tetrameric hemoglobin $(\mathrm{Hb})$ would be the first option for a blood substitute [1,2]. However, cell-free $\mathrm{Hb}$ appears to be toxic $[3,4]$ because its tetrameric structure is prone to dissociation into dimers, which then undergo rapid extravasation $[2,5]$. To prevent rapid tetramer elimination in blood substitute candidates, $\mathrm{Hb}$ is

\footnotetext{
a Babeş-Bolyai University, Department of Chemistry and Chemical Engineering, 11 Arany Janos Street, Cluj-Napoca 400028, Romania

b Technical University of Cluj-Napoca, Electrical Engineering and Measurements Department, 26

G. Baritiu Street, Cluj-Napoca 400027, Romania

* Corresponding author: rsilaghi@chem.ubbcluj.ro
} 
typically treated with agent(s) capable of increasing the apparent molecular weight of the protein and/or establishing covalent bonds between the subunits [1, 6-12]. In this respect, one of the most commonly used methods involves reticulation/polymerization with dialdehydes such as glutaraldehyde $[7,8,13-$ 15]. This reaction allows intermolecular bonding between the amino groups $(-\mathrm{NH} 2)$ of lysines (and $\mathrm{N}$-terminal valines) of $\mathrm{Hb}$ and the carbonyl groups $(-\mathrm{C}=\mathrm{O})$ of glutaraldehyde, with the formation of covalent-bonded dimers, trimers, tetramers and polymers $[7,9,16]$. Compared to $\mathrm{Hb}$ polymers, the $\mathrm{Hb}$-albumin copolymerization strategy has been reported to present key advantages in avoiding oxidative stress side-reactions, with minimal effects in biological tests $[9,11,17]$. Here, we describe a device for mixing the reactants in order to attain higher molecular weights with better reproducibility in the hemoglobin reticulation/polymerization reactions with glutaraldehyde, as well as for copolymerization reactions of hemoglobin with bovine serum albumin (BSA). The use of the described mixer allows for more informed and controlled choices in establishing protocols for producing protein-based oxygen carriers in larger quantities.

\section{RESULTS AND DISCUSSION}

\section{Mathematical modeling of the mixer}

The device employed for the mixing procedures was built in order to obtain a promptly homogeneous reaction mixture, from two to four species, in various concentrations, with the aid of an electromechanically delivery system and a mixing chamber.

The electromechanical system contains a stepper motor, an electronic circuit, the mechanical components, two to four syringes, and elastic connecting tubes. It can be adapted to different types of syringes, offering the possibility to easily modify the volumes of the chemicals that are involved in the reactions. The flow rate variation of the delivered species is also controllable via the velocity of the stepper motor, controlled via the electronic circuit. Figure 1 illustrates the flow rate through the connecting tubes as being a linear vs the stepper motor's angular velocity (regardless of its value), for a single-syringe case. 


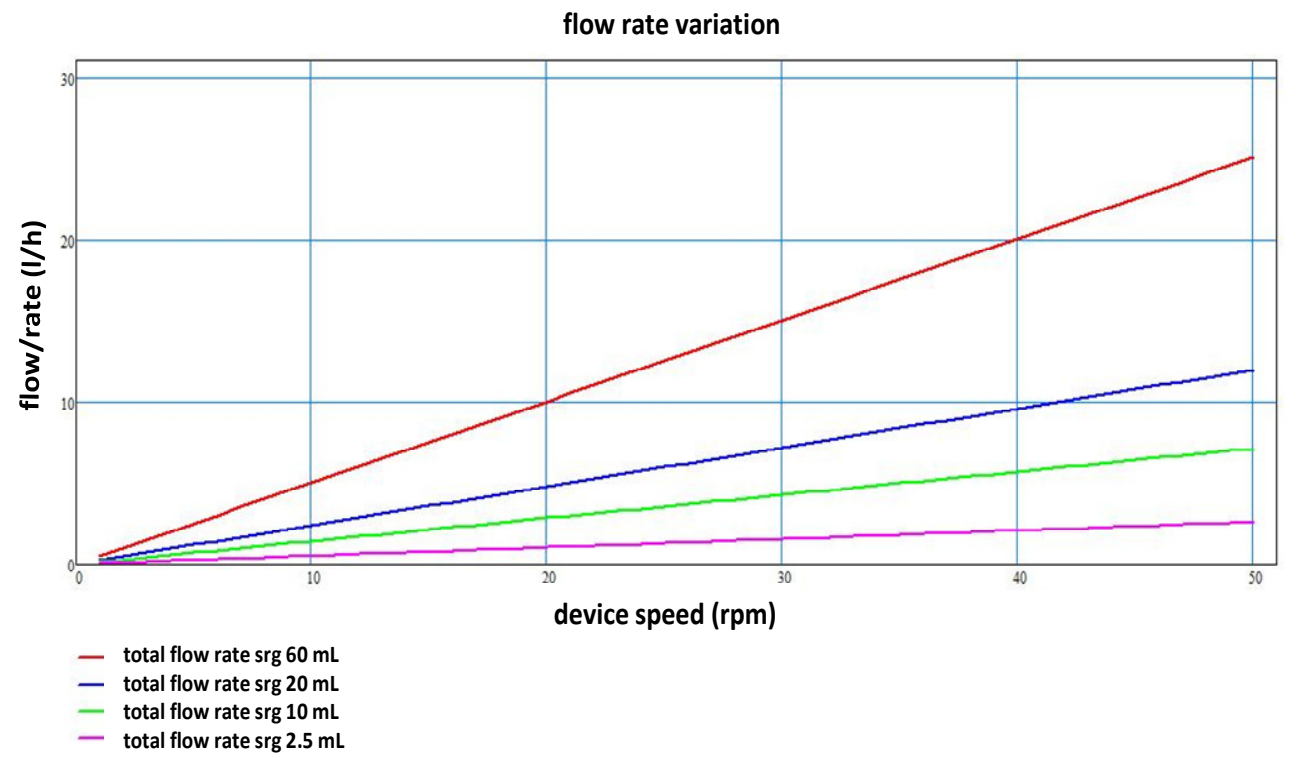

Figure 1. Flow rate variation for different syringe types $(2.5$ to $60 \mathrm{~mL})$.

The mixing device (cf. Figure 2) that was used for this case consists of a silicone tube and three syringe needles used for the two inlets and the outlet of the mixer. The whole assembly has a coating of elastic silicone in order to protect the mixing tube from external influences, and to avoid variation of internal pressure.

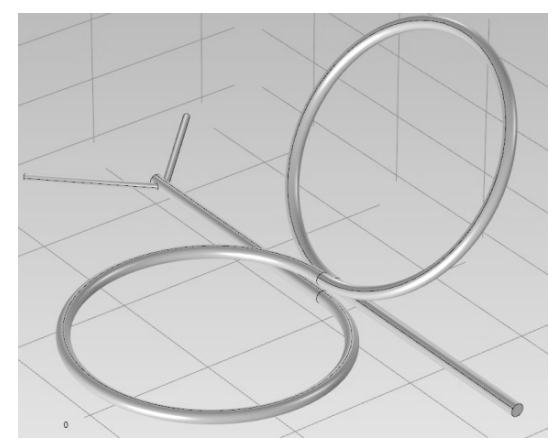

Figure 2. The mixing device and the interior geometry. Schematic representation.

The implementation of the mixing chamber was based on several tests and evaluations through mathematical modeling of the proposed geometry. The CFD modeling was performed for the physical model, with an initial velocity condition presumed at the inlet tubes of $0.5 \mathrm{~m} / \mathrm{s}$ for each species. 
The modeling result presented in Figure 3 shows that at the outlet of the mixing tube, the velocity of the mixture is around $2 \mathrm{~m} / \mathrm{s}$, and there are no significant turbulences. This value is sufficient to obtain a residence time, inside the mixer, of around $100 \mathrm{~ms}$.

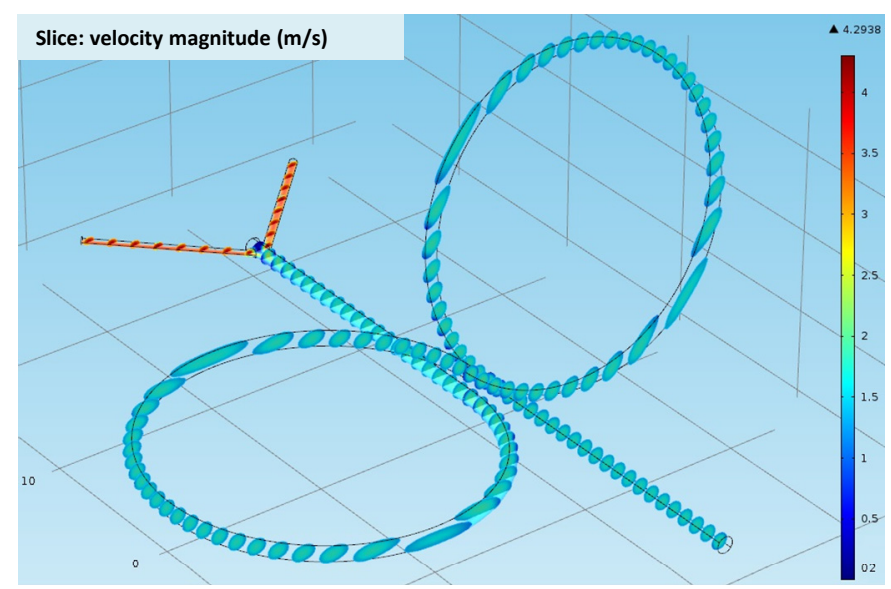

Figure 3. Velocity profile of the species in the mixing tube.

The results in Figure 4 illustrate the evolution of concentration only for the first species; for the second one the results are symmetrical. Thus, the outlet concentration of the substance is at half of its initial/inlet value suggesting that the species are indeed homogenously mixed and the chosen geometry can be successfully implemented.

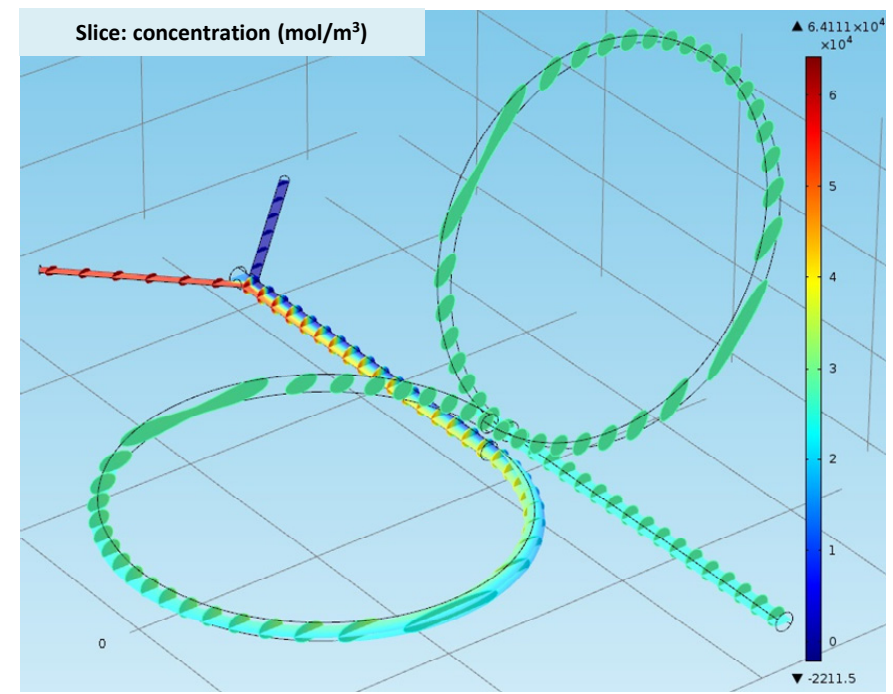

Figure 4. Concentration of the first species through the mixing tube. 


\section{FPLC-derived kinetics of the $\mathrm{Hb}-\mathrm{GL}$ and $\mathrm{Hb}-\mathrm{BSA}-\mathrm{GL}$ reactions}

The gel-filtration chromatograms in Figure 5 illustrate the changes in apparent molecular mass of $\mathrm{Hb}$, induced by polymerization with $8 \mathrm{mM}$ glutaraldehyde. The area under the peak corresponding to the derivatized sample (region to the left of the dashed vertical line in Figure 5) increases continuously with derivatization time, up to $120 \mathrm{~min}$. This value was proposed [7] as a reasonable time-point for obtaining suitable for blood substitute molecular weights.

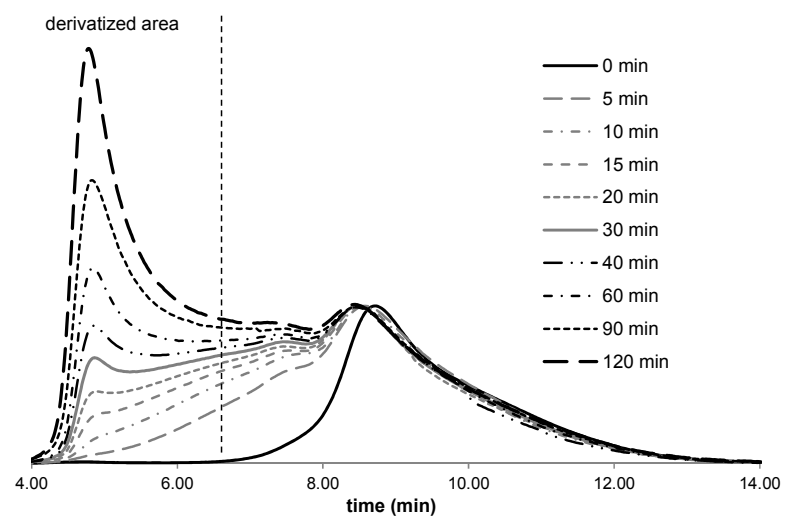

Figure 5. Size-exclusion chromatograms of $1 \mathrm{mM} \mathrm{Hb}$ derivatized with

$8 \mathrm{mM} \mathrm{GL}$, at different intervals after automated reactant mixing.

Conditions: $20 \mathrm{mM}$ Tris $\mathrm{pH}$ 7.4, $150 \mathrm{mM} \mathrm{NaCl}$, room temperature.

Figure 6 shows the time evolution of the Hb-BSA-GL ternary reaction mixture. The process appears to follow faster kinetics as compared to the simple $\mathrm{Hb}-\mathrm{GL}$ mixture, but with distinctly smaller contributions from fractions present near the front of the eluent (i.e., those with molecular weights of $1000 \mathrm{kDa}$ and higher).

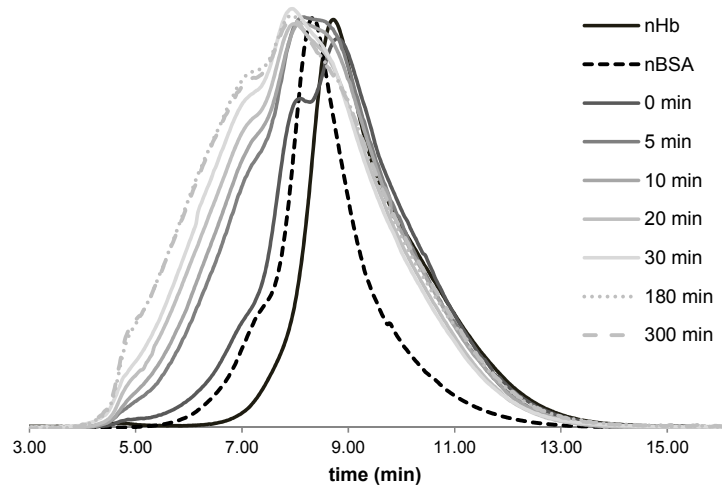

Figure 6. Size-exclusion chromatograms for $1 \mathrm{mM} \mathrm{Hb}$ derivatized with $1 \mathrm{mM}$ BSA in the presence of $8 \mathrm{mM} \mathrm{GL}$, at different intervals after reactant mixing.

Conditions: $20 \mathrm{mM}$ Tris $\mathrm{pH}$ 7.4, $150 \mathrm{mM} \mathrm{NaCl}$, room temperature. 


\section{SDS-PAGE-derived kinetics}

Figure 7 shows an SDS-PAGE analysis of the influence of glutaraldehyde (Figure 7A) and BSA (Figure 7B) on hemoglobin (co-)polymers, at different intervals after mixing. A clear trend is seen in the band corresponding to the $\mathrm{Hb}$ monomer at $\sim 16 \mathrm{kDa}$, as its intensity decreases constantly with the reaction time. The results are in agreement with those obtained by size exclusion chromatography: for the hemoglobin-only polymer the reaction is not completed after $120 \mathrm{~min}$, while in case of copolymer the reaction is completed after aprox. 30 min, in line with data in Figures 6 and 8B (see below).

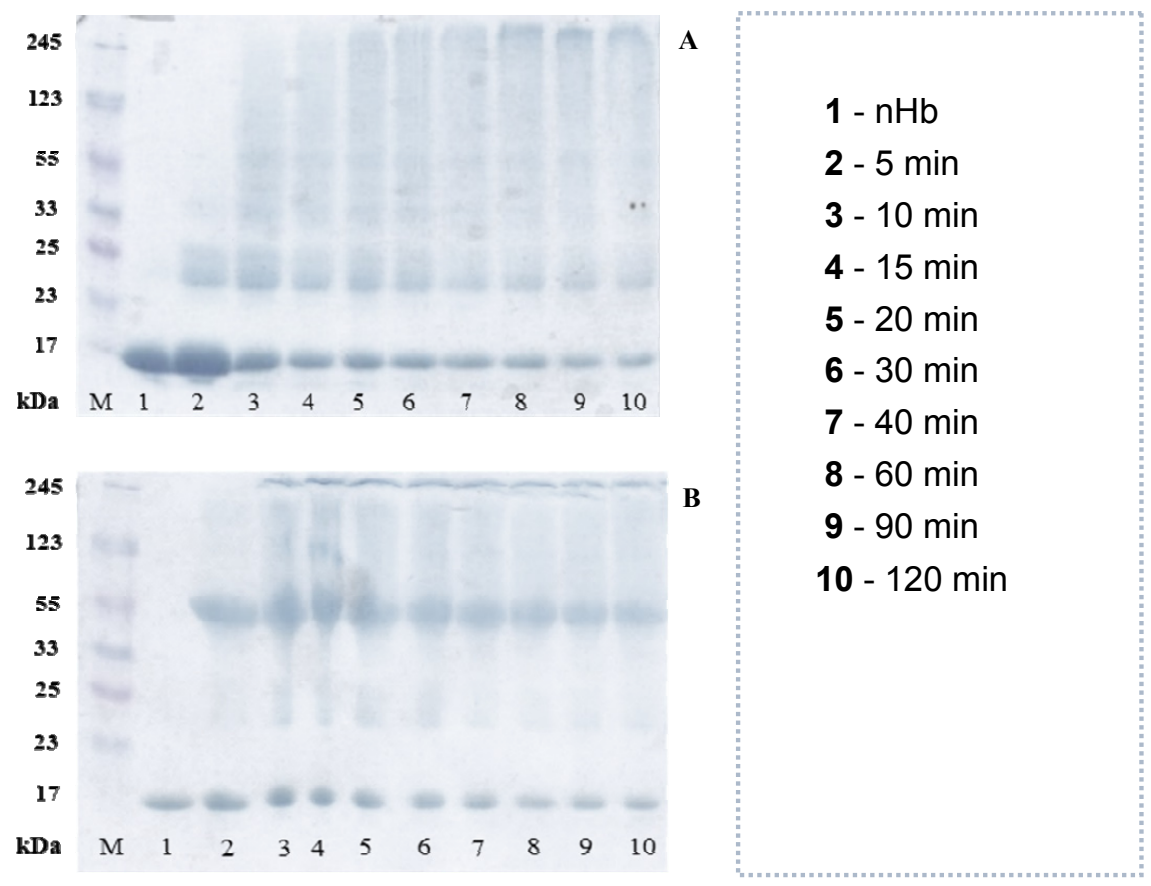

Figure 7. SDS-PAGE illustrating the effect of $8 \mathrm{mM}$ glutaraldehyde (A) and $1 \mathrm{mM}$ BSA (B) on polymerization degree, at different intervals after reactant mixing: 1- native $\mathrm{Hb}$, 2- $5 \mathrm{~min}$, 3- $10 \mathrm{~min}$, 4- $15 \mathrm{~min}$, 5- $20 \mathrm{~min}$, 6- $30 \mathrm{~min}$, 7- $40 \mathrm{~min}$, 8- $60 \mathrm{~min}, 9-90 \mathrm{~min}$, and 10- $120 \mathrm{~min}$.

Images of the gels were analyzed digitally (by using the specialized software called Thin Layer Chromatography Analyzer). Figure 8A (corresponding to polymerized $\mathrm{Hb}$ ) shows that the intensity of the monomer band (16 kDa) decreases constantly with the increase of reaction time, while the intensity of the polymer band $(245 \mathrm{kDa})$ increases, demonstrating the evolution of 
the polymerization reaction. By contrast, the line corresponding to the $\mathrm{Hb}$ copolymerized with BSA, maintains the same intensity as the line corresponding to the copolymerized sample with 120 min reaction time (Figure 8B), demonstrating that the copolymerization is completed after aprox. $30 \mathrm{~min}$.
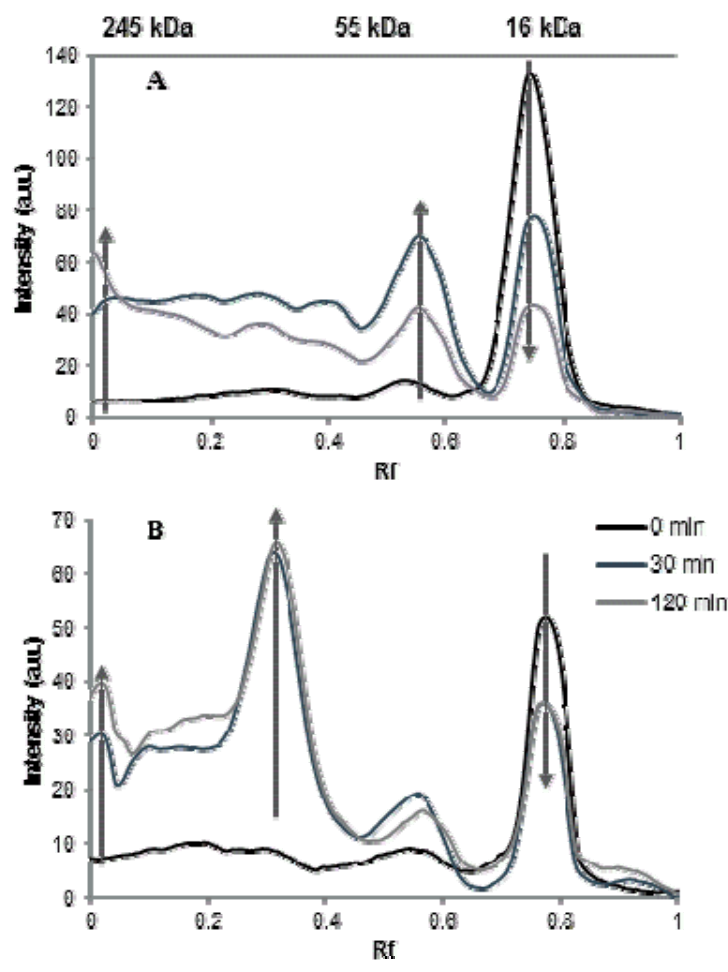

Figure 8. SDS-PAGE image analysis by a specialized software (A: $1 \mathrm{mM} \mathrm{Hb}+8 \mathrm{mM} \mathrm{GL}, \mathbf{B}: 1 \mathrm{mM} \mathrm{Hb}+1 \mathrm{mM} \mathrm{BSA}+8 \mathrm{mM} \mathrm{GL}$ )

\section{UV-vis characterization of the (co)polymers}

Figure 9 shows UV-vis spectra of derivatized $\mathrm{Hb}$ immediately after the derivatization procedure with or without BSA, when using glutaraldehyde as a cross-linking agent. The increase in absorbance at $630 \mathrm{~nm}$ (specific to ferric hemoglobin), coupled with decreases at 540 and $580 \mathrm{~nm}$ (specific to ferrousoxy hemoglobin), indicates that glutaraldehyde induces a slightly enhanced autooxidation tendency (higher concentration of derivatization agent causes higher autooxidation rate) - which, as also seen in Figure 9 (solid dark grey trace), BSA can alleviate. Similarly, higher reaction times increase the autooxidation tendency (Figure 10). Moreover, after approximately 4 hours the protein precipitates. 


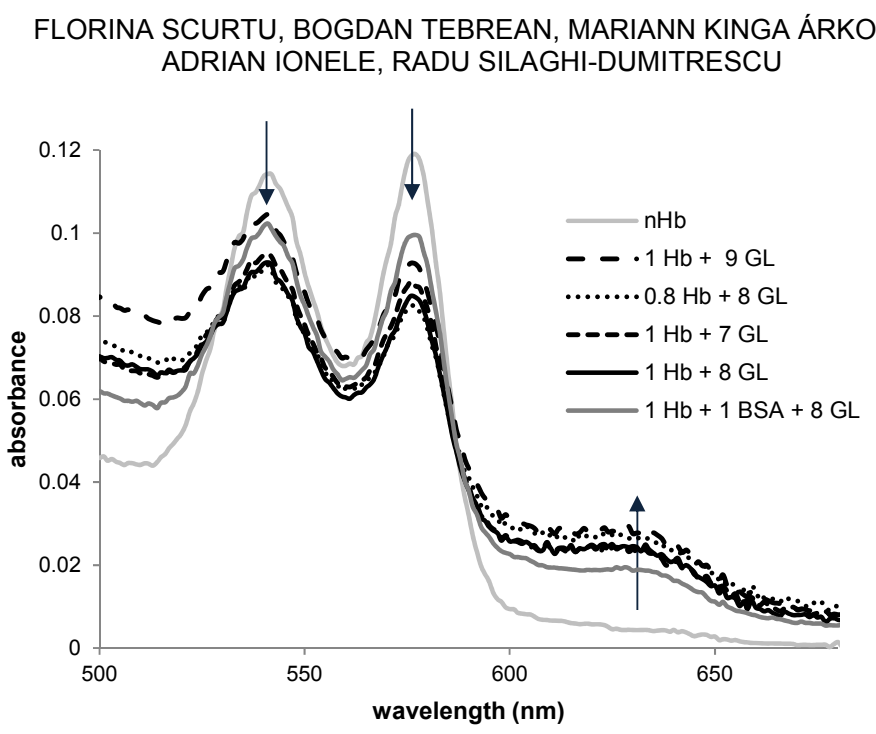

Figure 9. UV-VIS spectra of native and (BSA co)polymerized hemoglobin, measured after derivatization with glutaraldehyde at various concentrations (mM). Conditions: PBS, room temperature.

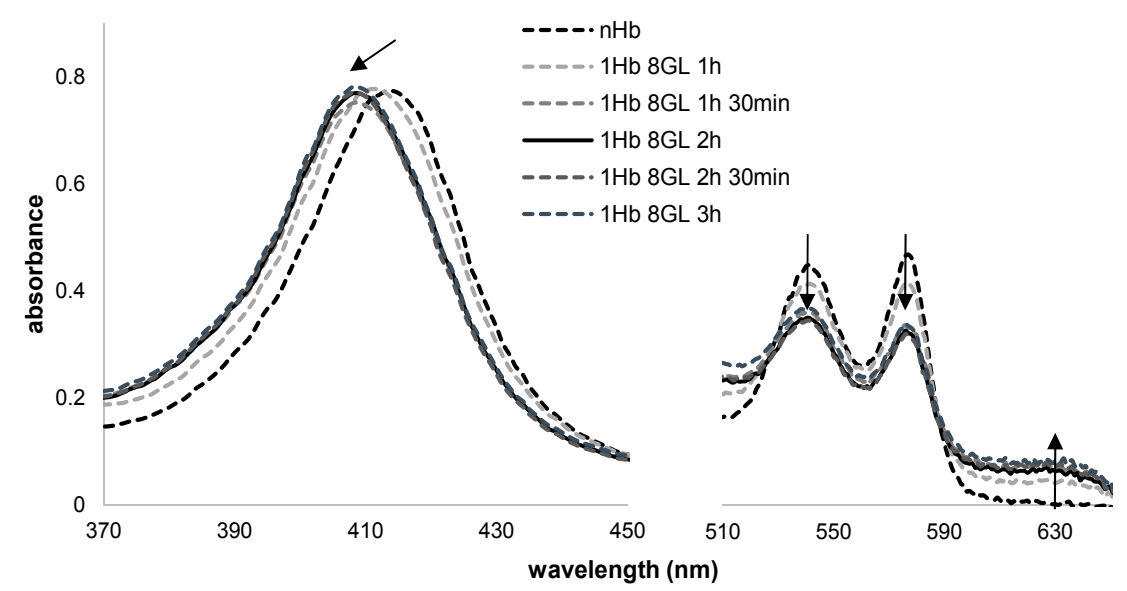

Figure 10. UV-VIS spectra of polymerized hemoglobin, measured after derivatization with glutaraldehyde at different time of reaction.

Conditions: $1 \mathrm{mM} \mathrm{Hb}, 8 \mathrm{mM} \mathrm{GL}$, PBS, room temperature.

\section{Influence of reactant concentration}

Figure 11 illustrates that the degree of polymerization increases with the concentration of derivatizing agent. Thus, the largest derivatized area was obtained in the sample with the highest concentration of glutaraldehyde 
(see Table 1). Again, one may note that the reaction is still incomplete at 120 min after mixing in the $\mathrm{Hb}-\mathrm{GL}$ cases, while it is essentially completed after $30 \mathrm{~min}$ for the $\mathrm{Hb}$-BSA mixtures. Although the derivatized area is higher after 180 minutes, the reaction is optimally quenched at 120 min because at longer times there are also higher autoxidation rates in the product (see Figure 10). Time resolved data in Figure 10 were fitted with the exponential growth function $y=A_{1}{ }^{*} \exp \left(x / t_{1}\right)+A_{2}{ }^{*} \exp \left(x / t_{2}\right)+y_{0}$, in order to obtain the kinetic data in Table 1.

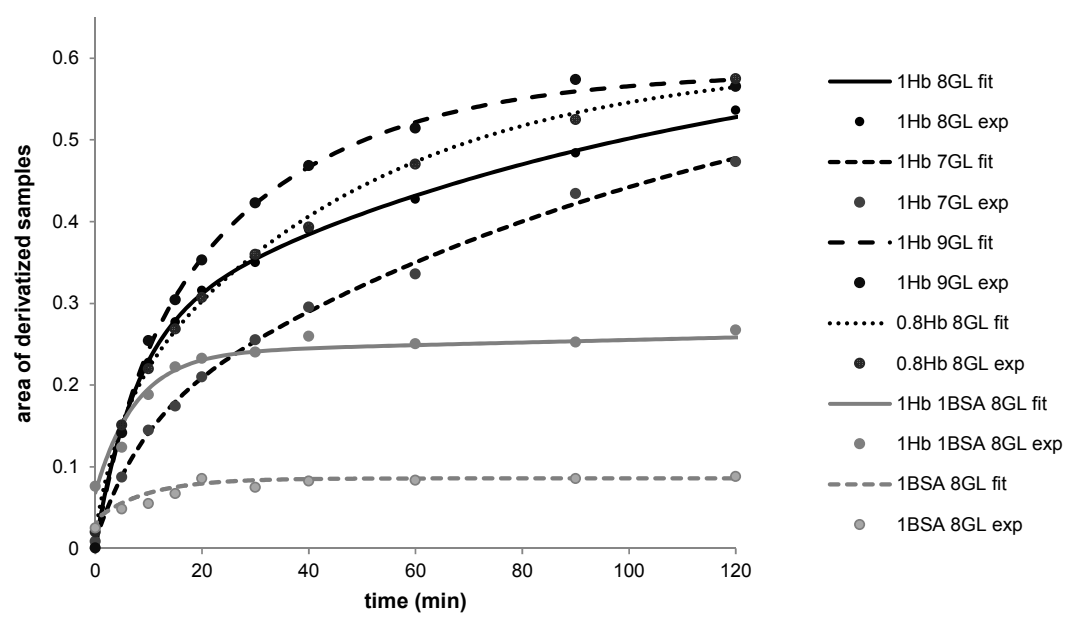

Figure 11. Time course evolution of derivatized $\mathrm{Hb}$ at various reactant concentrations.

Table 1. Derivatized area of the analyzed samples and fitted parameter values.

\begin{tabular}{|c|c|c|c|c|c|c|}
\hline Sample & $\begin{array}{c}\text { Derivatized area } \\
\text { after } 120 \text { min of } \\
\text { reaction } \\
\text { (a.u } \cdot \text { time. })\end{array}$ & $\begin{array}{c}A_{1} \\
\text { (a.u.) }\end{array}$ & $\begin{array}{c}t_{1} \\
(\mathrm{~min})\end{array}$ & $\begin{array}{c}A_{2} \\
\text { (a.u. })\end{array}$ & $\begin{array}{c}\boldsymbol{t}_{2} \\
(\min )\end{array}$ & $R^{2}$ \\
\hline $1 \mathrm{mMHb}+7 \mathrm{mMGL}$ & 114 & 0.53 & 117.28 & 0.13 & 8.43 & 0.99 \\
\hline $1 \mathrm{mM} \mathrm{Hb}+8 \mathrm{mMGL}$ & $125^{*}$ & 0.27 & 8.08 & 0.53 & 188.22 & 0.99 \\
\hline $1 \mathrm{mMHb}+9 \mathrm{mMGL}$ & 140 & 0.17 & 6.79 & 0.41 & 31.34 & 0.99 \\
\hline $0.8 \mathrm{mM} \mathrm{Hb}+8 \mathrm{mM} \mathrm{GL}$ & 132 & 0.17 & 6.28 & 0.45 & 66.22 & 0.99 \\
\hline $\begin{array}{c}1 \mathrm{mM} \mathrm{Hb}+1 \mathrm{mM} \mathrm{BSA}+ \\
8 \mathrm{mM} \mathrm{GL}\end{array}$ & 129 & 0.09 & 10.7 & 0.09 & 10.7 & 0.97 \\
\hline $1 \mathrm{mMBSA}+8 \mathrm{mMGL}$ & 40 & 1154.36 & 2.17 & 0.06 & 10.11 & 0.91 \\
\hline
\end{tabular}

${ }^{*}$ for this mixture, areas at 180 and 240 min were also recorded; of 198 and 155 a.u. · time, respectively 
Figure 12 compares chromatograms of samples obtained by mixing the reactants manually and when using the mixer, at different time intervals. It is important as well as useful that the derivatized area is larger in the case of automatically mixed reactants. The better homogeneity of the reaction mixture also provides a better uniformity of the resulted aggregates (in terms of molecular weight), and also leads to better reproducibility.

\section{$1 \mathrm{mM} \mathrm{Hb}+8 \mathrm{mM} \mathrm{GL}$}
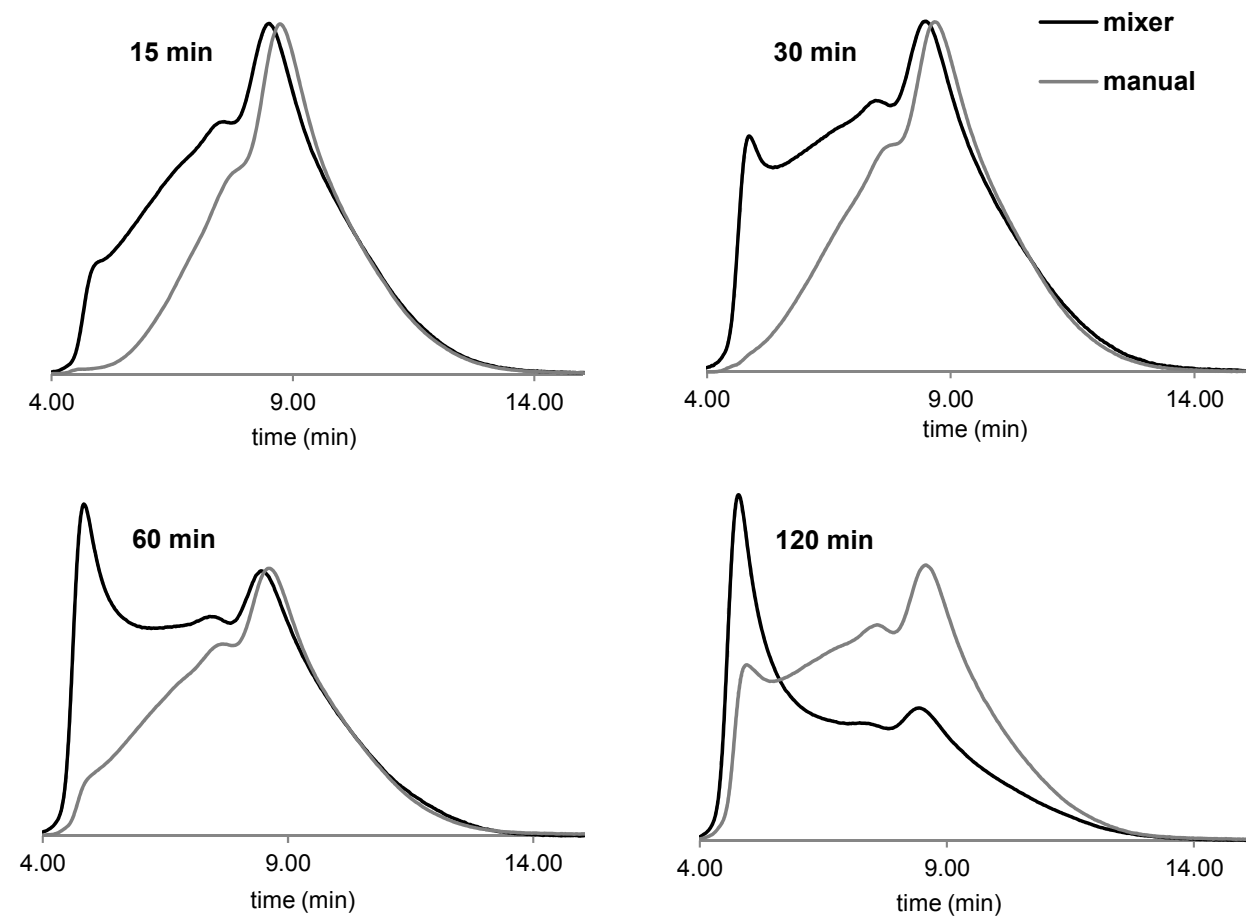

Figure 12. Size-exclusion chromatograms of $\mathrm{Hb}$ derivatized with $8 \mathrm{mM} \mathrm{GL}$ at different time intervals after mixing the reactants either manually, or with the mixer.

\section{CONCLUSIONS}

The kinetics of the derivatization reaction of hemoglobin and albumin with glutaraldehyde have been revisited, in order to establish the optimal conditions (time of reaction, concentration of protein and derivatization agent) for which the final product would be a reasonable candidate for blood substitutes. The use of an automated mixing device (with a tens-of-milliseconds mixing time) allows for polymers with a distinctly more reproducible molecular weight, compared with manual mixing under magnetic stirring. The importance of 
dedicated mixing devices for protein derivatization, discussed here for the glutaraldehyde-based reticulation of hemoglobin and albumin, is likely an observation valid more generally for performing relatively fast (bio)chemical reactions.

\section{EXPERIMENTAL SECTION}

Mixer. The mixer is built from a nonporous redox-inert material, which may be metal or plastic. Its constraints are: (1) it should be impermeable and (2) should not be oxidized by water and oxygen. In order for the mathematical model to embed the key issues relevant for building a mixer relevant for blood substitute solutions, two aqueous solutions were considered - GL ( $0.1 \%$ glutaraldehyde) and $\mathrm{Hb}$ (3.2\% hemoglobin), and the initial conditions shown in Table 2 were imposed.

Table 2. Experimental conditions for the mixer building

\begin{tabular}{|l|l|}
\hline Parameters & Value \\
\hline Glutaraldehyde final concentration & $0.1[\mathrm{~g} / \mathrm{l}]$ \\
\hline Hemoglobin final concentration & $16[\mathrm{~g} / \mathrm{l}]$ \\
\hline Diffusion coefficient $\left(D_{\mathrm{GL}-\mathrm{Hb}}\right)$ & $4.5^{\star} 10^{-9} \mathrm{~m}^{\wedge} 2 / \mathrm{s}$ \\
\hline Density $\left(\rho_{\mathrm{GL}}, \rho_{\mathrm{Hb}}\right)$ & $\rho_{\mathrm{GL}}=\rho_{\mathrm{Hb}}=1 \mathrm{~kg} / \mathrm{m}^{\wedge} 3$ \\
\hline Dynamic viscosity $\left(\mu_{\mathrm{GL}}, \mu_{\mathrm{Hb}}\right)$ & $\mu_{\mathrm{GL}}=\mu_{\mathrm{Hb}}=1 \mathrm{mPa}{ }^{*} \mathrm{~s}$ \\
\hline Temperature & $4^{\circ} \mathrm{C}$ \\
\hline Flow rate (total) & $\mathrm{Q}=11 / \mathrm{h}$ (may vary as needed) \\
\hline Pressure drop & $1 \mathrm{~atm}$ \\
\hline Residence time of the mixed substance & $100 \mathrm{~ms}$ \\
\hline
\end{tabular}

Hemoglobin purification. Bovine hemoglobin was purified by following the general protocol of Antonini and Brunori [18]. Concentrations in the text are given per heme rather than tetramer. Native, non-derivatized hemoglobin or bovine serum albumin is hereafter referred to as "nHb" and "nBSA", respectively.

Protein derivatization. PolyHb and copolyHb-BSA were obtained by mixing a $\mathrm{nHb}$ solution with or without a BSA (fraction V, Sigma, Germany) solution, with glutaraldehyde (Sigma, Germany) at $4^{\circ} \mathrm{C}$, at concentrations indicated in text. The reaction was stopped by addition of $\mathrm{NaBH} 4$ in equimolar amount to the glutaraldehyde. The borohydride reduces imine bonds to stable amines and also quenches excess carbonyl groups. After quenching, the reaction mixtures were dialyzed against $20 \mathrm{mM}$ Tris buffer, $150 \mathrm{mM} \mathrm{NaCl}$ at $\mathrm{pH} 7.4$, to remove excess $\mathrm{NaBH}_{4}$ and side-products, respectively $[7,9]$. 
Mixing procedures. The samples were mixed either manually, using the tip of the automated pipette upon addition of the GL to the protein solution in a $1.5-\mathrm{mL}$ reaction vessel, or by using a purpose-designed mixer. In the latter case, the protein and GL solutions are introduced into two different syringes, the fluids being then directed towards the mixing chamber, through separate tubes driven by a mobile plate with a constant speed. Here, the reactants are mixed in a ratio decided by the diameters of the tubing and syringes (in all experiments this was 1:1), allowing attainment of a homogeneous reaction mixture (see Figure 13).

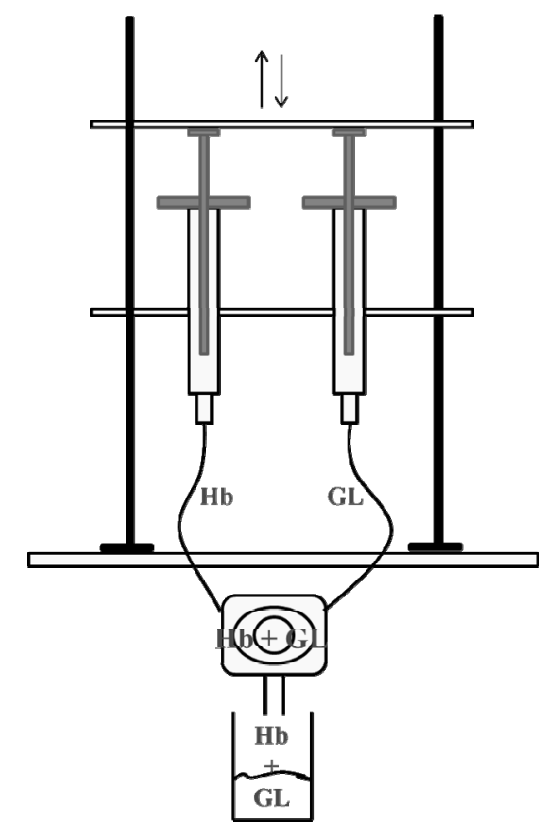

Figure 13. Schematic representation for the mixing device employed for hemoglobin polymerization.

SDS-PAGE. The polymerization yield was assessed using 15\% SDSPAGE (sodium dodecyl sulfate polyacrylamide gel electrophoresis). The gels generally consist of acrylamide, bisacrylamide, SDS, Tris-Cl buffer with adjusted $\mathrm{pH}$, ammonium persulfate and TEMED (N,N,N',N'-Tetramethyl ethylenediamine).

Fast protein liquid chromatography (FPLC, GE Healthcare, Sweden) was employed for determining the percentage of total cross-linked $\mathrm{Hb}$. A Superdex $2005 / 150 \mathrm{GL}$ size exclusion column with $0.25 \mathrm{~mL} / \mathrm{min}$ flow rate was used, with a mobile phase of $20 \mathrm{mM}$ Tris buffer, $150 \mathrm{mM} \mathrm{NaCl}$ at pH 7.4. The absorbance was monitored at $280 \mathrm{~nm}$. Samples retrieved from the 
HEMOGLOBIN-ALBUMIN CO-POLYMERS FOR BLOOD SUBSTITUTES: INCREASING THE REPRODUCIBILITY OF THE POLYMERIZATION REACTION

reaction mixture at various times in the interval of $0-120$ minutes, were each analyzed on the analytical gel-filtration column. The areas under the peaks corresponding to derivatized hemoglobin were used as measure of the polymerization degree and apparent molecular weight.

UV-VIS spectra were recorded on a Cary 50 (Varian, Inc) instrument in PBS 7.4.

\section{ACKNOWLEDGMENTS}

Financial support from the Romanian Ministry for Education and Research (grant PCE 488/2012) is gratefully acknowledged. Florina Scurtu also thanks the Babeş-Bolyai University of Cluj-Napoca for financial support by means of the Sectoral Operational Programme for Human Resources Development 2007-2013, co-financed by the European Social Fund, under the project POSDRU/159/1.5/S/132400 - "Young successful researchers - professional development in an international and interdisciplinary environment".

\section{REFERENCES}

1. A. I. Alayash, Nature Reviews. Drug Discovery, 2004, 3, 152-159.

2. C. L. Modery-Pawlowski, L. T. Lewis, V. Pan, A. Sengupta, Biomacromolecules, 2013, 14, 939-948.

3. A. I. Alayash, R. E. Cashon, Annals of the New York Academiy of Sciences, 1994, 738, 378-381.

4. A. I. Alayash, Free Radical Biology and Medicine, 1994, 16, 137-138.

5. J. G. Riess, Chemical Reviews, 2001, 101, 2797-2919.

6. T. M. S. Chang, Artificial Organs, 2004, 28, 789-794.

7. F. Deac, A. Todea, R. Silaghi-Dumitrescu, "Glutaraldehyde derivatization of hemoglobin: a potential blood substitute", In Metal Elements in Environment, Medicine and Biology Tome IX (Silaghi-Dumitrescu, R.; Garban, G., Eds.), pp 165-173, Cluj University Press, Cluj-Napoca, Romania, 2009.

8. F. Scurtu, A. Mot, R. Silaghi-Dumitrescu, Pharmaceuticals, 2013, 6, 867-880.

9. F. Scurtu, O. Zolog, B. lacob, R. Silaghi-Dumitrescu, Artificial Cells, Blood Substitutes, and Immobilization Biotechnology, 2014, 42, 13-17.

10. F. Deac, B. lacob, E. Fischer-Fodor, G. Damian, R. Silaghi-Dumitrescu, Journal of Biochemistry (Tokyo), 2011, 149, 75-82.

11. B. lacob, F. Deac, D. Cioloboc, G. Damian, R. Silaghi-Dumitrescu, Artificial Cells, Blood Substitutes, and Immobilization Biotechnololy, 2011, 39, 293-297.

12. O. Zolog, A. Mot, F. Deac, A. Roman, E. Fischer-Fodor, R. Silaghi-Dumitrescu, The Protein Journal, 2011, 30, 27-31.

13. W. H. Chang, Y. Chang, Y. C. Chen, H. W. Sung, Artificial Cells, Blood Substitutes, and Immobilization Biotechnology, 2004, 32, 243-262.

14. H.-W. Kim, A. Greenburg, Artificial Organs, 2004, 28, 813-827. 
FLORINA SCURTU, BOGDAN TEBREAN, MARIANN KINGA ÁRKOSI, ADRIAN IONELE, RADU SILAGHI-DUMITRESCU

15. A. I. Alayash, Clinics in Laboratory Medicine, 2010, 106, 76-85.

16. A. I. Alayash, Trends in Biotechnology, 2014, 32, 177-185.

17. A. N. Fedorov, V. S. larochkin, V. B. Koziner, A. A. Hachaturian, G. I. Rozenberg, Doklady Akademii Nauk SSSR, 1978, 243, 1324-1326.

18. E. Antonini, M. Brunori, "Hemoglobin and Myoglobin in their Reaction with Ligands", North-Holland, Amsterdam, 1971. 